\title{
A Statistical Comparison of NRHM 2007-08 and 2012-13 Survey Data
}

\author{
Vikram Singh $^{1}$, Santosh Kumar Gupta ${ }^{1}$, Jagdish Prasad ${ }^{2, *}$ \\ ${ }^{1}$ Department of Statistics, University of Rajasthan, Jaipur Rajasthan, India \\ ${ }^{2}$ Amity School of Applied Sciences, Amity University Rajasthan, Jaipur, India \\ Email address: \\ vs26262@gmail.com (V. Singh), gupta-sk@uniraj.ernet.in(S. K. Gupta),jagdish55_singh@yahoo.com(J. Prasad) \\ ${ }^{*}$ Corresponding author
}

\section{To cite this article:}

Vikram Singh, Santosh Kumar Gupta, Jagdish Prasad. A Statistical Comparison of NRHM 2007-08 and 2012-13 Survey Data. American Journal of Theoretical and Applied Statistics. Vol. 8, No. 6, 2019, pp. 240-245. doi: 10.11648/j.ajtas.20190806.15

Received: June 11, 2019; Accepted: August 15, 2019; Published: November 15, 2019

\begin{abstract}
Important of health in the process of economic and social development and improving the quality of life of our citizens, the Government of India has launched the National Rural Health Mission. District level Household and Facility survey DLHS-3 and DLHS-4 conducted by Ministry of Health and family Welfare of New Delhi and International Institute for Population Science of Mumbai in 2007-08 and 2012-13 for Rajasthan. These surveys provide effective health care to rural population in the state, which has poorer health outcomes and inadequate public health infrastructure and manpower. The primary focus of the mission is the improve access of rural people, especially women and children, to equitable and affordable primary health care. In this paper the infrastructure facility in SHC, PHC and CHC has been increased from 2007-08 to 201213 NRHM DLHS is assesses through statistical analysis. Facility survey is carried out for the central and state government in evaluation monitoring and planning strategies.
\end{abstract}

Keywords: Official Statistics, DLHS (District Level Household and Facility Survey), International Institute for Population Sciences (IIPS), Indian Public Health Standards (IPHS)

\section{Introduction}

Three rounds of District Level Household and Facility Surveys (DLHS) has the main objective to provide reproductive and child health database at Rajasthan. These surveys are useful for the central and state governments in evaluation, monitoring and planning strategies. Facility Survey provide information on the availability and utilization of services at District Hospital (DH), Sub-divisional hospital (SDH), Community Health Centre (CHC), Primary Health Centre (PHC) and Sub Health Centre (SHC). A village health plan prepared through a local team headed by the Health \& Sanitation Committee of the Panchayat: strengthening of the rural hospital for effective curative care and made measurable and accountable to the community through Indian Public Health Standards (IPHS); and integration of vertical Health \& Family Welfare Programmes and Funds for optimal utilization of funds and infrastructure and strengthening delivery of primary healthcare.
A multi-stage stratified systematic sampling design was adopted for DLHS-3. In rural areas, villages were selected by probability proportional to size (PPS) systematic sampling and in the second stage households were selected by systematic sampling. For urban areas first wards were selected by PPS systematic sampling, in the second stage census enumeration blocks (CEB's) by PPS sampling and households in the third stage by systematic sampling.

In the facility survey, the information collected at the SHC level were availability of the human resources, physical infrastructure, equipment's and essential drugs and $\mathrm{MCH}$ service provided in on month preceding the survey. From, the PHC, status of availability for $24 * 7$ facility and services for delivery and newborn care were also collected.

The mode of collection of information for health facilities was collated by the method of personal interaction with the concerned officials, physical inspection and recording from relevant registers. 


\section{Review of Literature}

In this section, some relevant studies and research done by different authors is discussed.

In 2007-08 [1], Indian government conduct the survey related to health facility.

In 2012-13 [2], Health facility data provided by national rural health mission.

In 1990, Garner [3], gave the overall picture of how well rural health services in the country were running and showed that managerial weaknesses at provincial and local levels were contributing to poor functioning at some of the centers, with regional variation in the amount of medical supervisory visits.

In 1995 [4], examined the relationship between infrastructure and the level of community economic development. And also found that infrastructure is a significant, positive determinant of economic performance.

In 1999 [5], used the health facility survey in which all health facilities are identified, surveyed and located geographically. They have applied multivariate analysis almost all characteristics of both provider and facilities are found to have the a priori expected relationships to facility choice.

In 2008 [6], has examined empirically the place of infrastructures in the agricultural productivity of majority from households in Nigeria by using the Total Factor Productivity (TFR) and the Ordinary Least Square (OLS) regression. They have proved that Rural infrastructure significantly influence farms productivity levels.

In 2008, Cimellaro [7], has explained the conceptual framework and organizational model which is able to estimate the hospital capacity and its dynamic response in real time and incorporate the influence of the facility's damage in structural and non-structural systems on the organizational ones.

In 2010, Schoeman [8], has assessed the primary health care facility infrastructure and services and the nutritional status of 0 to 71 month-old children and their caregivers attending PHC facilities in the Eastern Cape and KwaZulaNatal provinces in South Africa.

In 2012, KaulSapna [9], has showed that only one is five birth take place at a health facility in Bihar, India and recommended that awareness should be spread and more investment in health infrastructure in Bihar.

In 2012, Kavitha [10], has showed that the restructuring has focused on finding effective ways to satisfy the needs and desires of the patients.

In 2013, Patra [11], showed that An agrarian structure predominated by small and marginal farmers; and repeated natural calamities like droughts, floods and cyclones and poor infrastructural development in the hilly terrain of western and southern Odisha. Multiple Regression Analysis was used to know how the State Government Capital Expenditure (SGCE) and State Government Revenue Expenditures (SGRE) on health and family welfare have influenced the health indicators like infant mortality rate, birth rate, death rate, etc.

In 2014, Ray [12], has presented the study on awareness \& utilization of National Rural Health Mission services among rural people in Maharashtra which was conducted keeping in mind to evaluate the percentage of people aware and utilize the NRHM services.

In 2015 [13], determining that the availability of infrastructure and access to the infrastructure. It helps in ranking areas based on the availability and access to infrastructure. In the present paper weights for the available infrastructure for one Rural Administrative Unit (RAU) have been calculated using Weighted Index Method, entropy method, WIM and Grey Relation Analysis have been used to determining the overall facility index.

In 2017, Abdelhalim [14], has given the graphing and mapping of some of the health facilities and progress of growth of health in Saudi Arabia.

In 2017 [15], critically evaluate the implementation of national rural health mission and highlighted its success and to make recommendations on the future health care planning and implementation in achieving universal health coverage for the rural India.

\section{Objectives}

The present paper aims to apply statistical analysis of NRHM Survey of health service in Rajasthan.

1. To find out that regular electricity, water facility, toilet facility and labor room facility in SHC has been increased from 2007-08 to 2012-13 NRHM survey.

2. To find out that Medical officer, Lady medical officer, ayush doctor, pharmacist, and residential quarter for M.O., PHC functioning 24 hours, at least 4 beds available, Regular electricity power supply, having functional vehicle, referral service for delivery and conducted at least 10 deliveries in PHC has been increased from 2007-08 to 2012-13 NRHM survey.

3. To find out that Obstetric Gynecologist, pediatrician, anesthetist and health manager facility increased from 2007-08 to 2012-13 NRHM survey in CHC.

\section{Analysis}

The survey data from 2007-08 to 2012-13 NRHM were examined on the basis of these surveys data we assesses that the variables proportion from 2007-08 to 2012-13 are same.

Suppose that both year Population variables are same for 2007-08 and 2012-13. So null i.e.

Null hypothesis

$$
H_{0}: P_{1}=P_{2}
$$

Alternative hypothesis

$$
H_{1}: P_{1}<P_{2} \text { or } P_{1}>P_{2}
$$

$n_{1}$ and $n_{2}$ are the sample sizes conduct by NRHM in year 2007-08 and 2012-13. 
First sample size is 785 and second sample size is 989 for Sub Health Center and First sample size is 692 and second sample size is 722 for Primary Health Center and Similarly first sample size is 355 and second sample size is 448 for Community Health center in Rajasthan.

For Large sample size Z-Test is Used for statistical analysis of comparison of NRHM survey conducted in year 2007-08 and 2012-13.

$$
Z=\frac{p_{1-} p_{2}}{\sqrt{\widehat{\mathrm{P}} \hat{Q}\left(\frac{1}{n_{1}}+\frac{1}{n_{2}}\right)}}
$$

Where

$$
\widehat{\mathrm{P}}=\frac{\mathrm{n}_{1} \mathrm{p}_{1}+\mathrm{n}_{2} \mathrm{p}_{2}}{n_{1}+n_{2}}
$$

and

$$
\widehat{Q}=1-\widehat{P}
$$

\subsection{Sub Health Centre: Water Facility}

At the Rajasthan, the proportion of SHCs housed in government buildings which are getting water supply through piped, bore well, hand pump or any other sources is not significant both $5 \%$ and $1 \%$ level of significance. Hence, Ho may be accepted. We may conclude that sample proportion of both population do not differ significantly.

\section{2. $\mathrm{PHC}$}

\subsubsection{Residential Quarter for Medical Officer}

The availability of staff quarters of doctors is significant both $5 \%$ and $1 \%$ level of significance. Hence, Ho may be rejected. We may conclude that sample proportion of both population do differ significantly.

\subsubsection{At Least 10 Deliveries Conducted}

The availability of at least 10 deliveries conducted by PHC is significant both $5 \%$ and $1 \%$ level of significance. Hence, Ho may be rejected. We may conclude that sample proportion of both population do differ significantly.

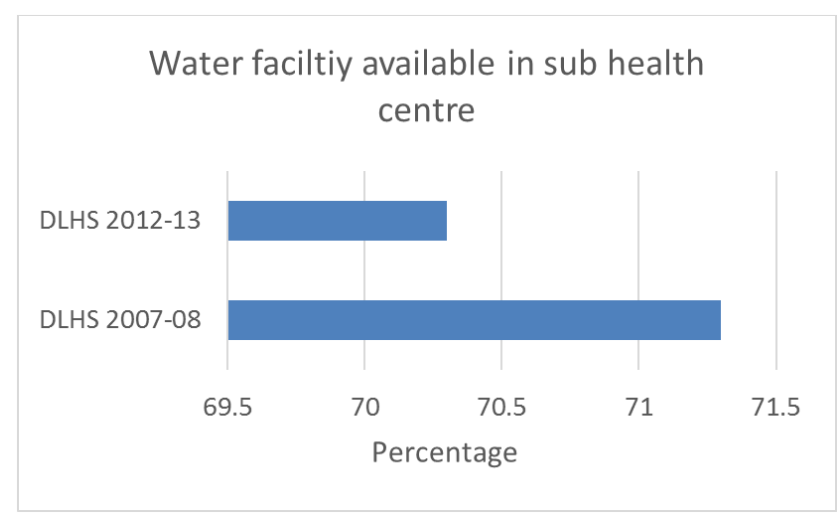

Source: DLHS by Ministry of Health and family welfare Government of India

Figure 1. Percentage of Water facility available in sub health Centre in whole Rajasthan.

\subsubsection{Lady Medical Officer}

Hypothesis assumption is that apply one tailed test for both $1 \%$ and $5 \%$ level of significance null hypothesis is PHC functioning 24 hours improvement in year 2012-13 compare to year 2007-08 is significant difference by this method.

DLHS survey of PHC also shows that Lady Medical officer is improvement in year 2012-13 compare to year 2007-08. But Hypothesis assumption is that apply one tailed test for both $1 \%$ and $5 \%$ level of significance null hypothesis is Lady M. O. improvement in year 2012-13 compare to year 2007-08 is not significant difference by this method. So both sample size data of NRHM is same.

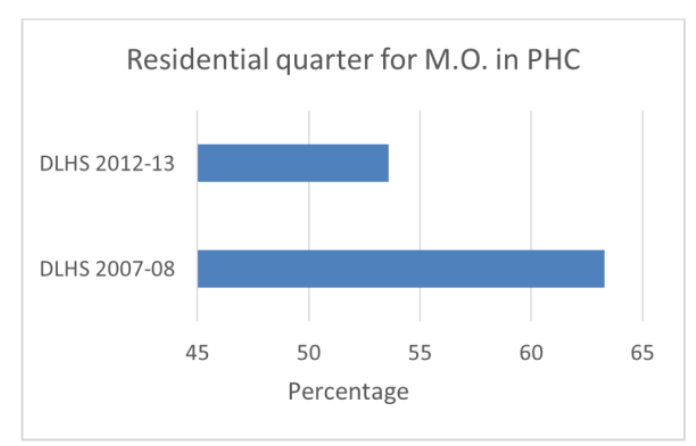

Source: DLHS by Ministry of Health and family welfare Government of India

Figure 2. Percentage of Residential quarter for medical officer in PHC in whole Rajasthan.

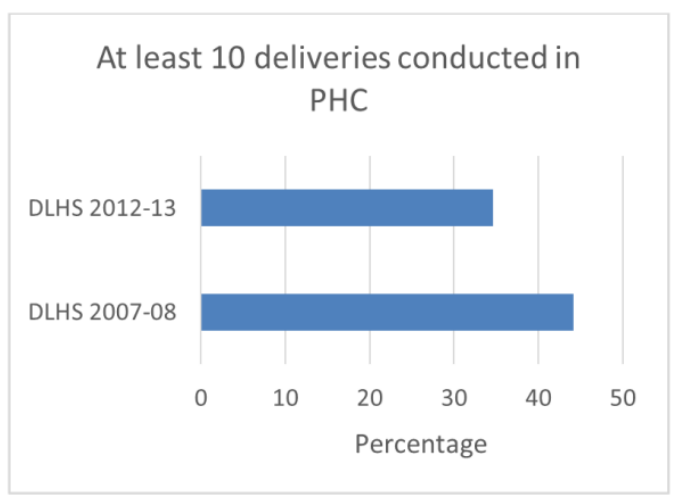

Source: DLHS by Ministry of Health and family welfare Government of India

Figure 3. Percentage of At least 10 deliveries conducted by PHC in whole Rajasthan.

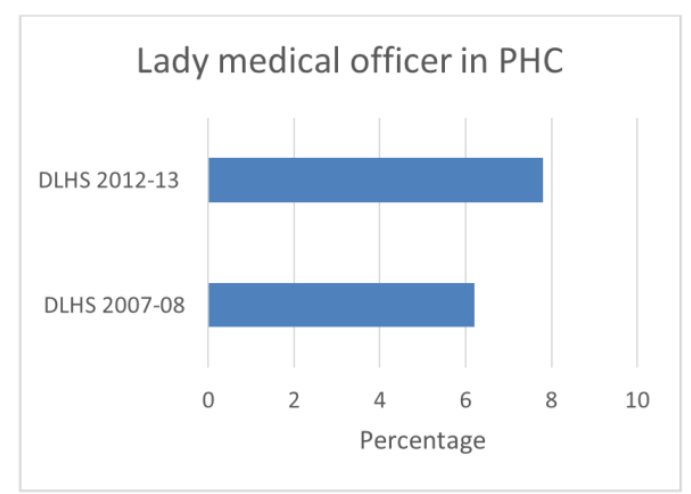

Source: DLHS by Ministry of Health and family welfare Government of India

Figure 4. Percentage of Lady Medical Officer in PHC in whole Rajasthan. 


\subsubsection{Pharmacist}

It is important to have a pharmacist at PHCs for drug storage and drug dispensing. Only 1.8 and 0.7 percent of the PHCs are having Pharmacist in position in Rajasthan in DLHS year 2012-13 and year 2007-08 continuously. Improvement showed by this data but this assumption also wrong because there is significant difference $5 \%$ level of significance but not significant difference at $1 \%$ level of significance one tailed test in $\mathrm{Z}$ statistics.

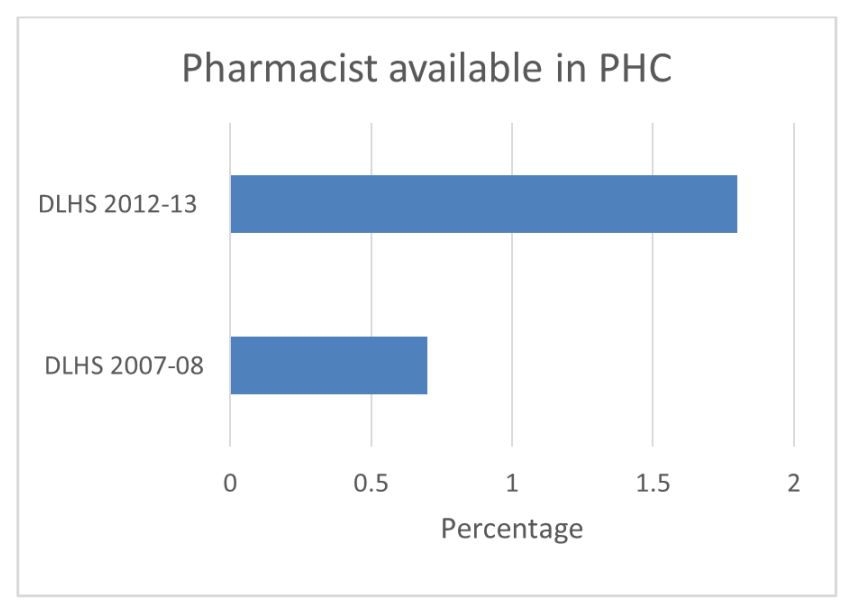

Source: DLHS by Ministry of Health and family welfare Government of India

Figure 5. Percentage of Pharmacist available in PHC in Rajasthan.

\subsection{CHC: Anesthetist}

The situation of posting anesthetist is significant difference at $5 \%$ and $1 \%$ level of significance. So population of both 2007-08 and 2012-13 is not same.

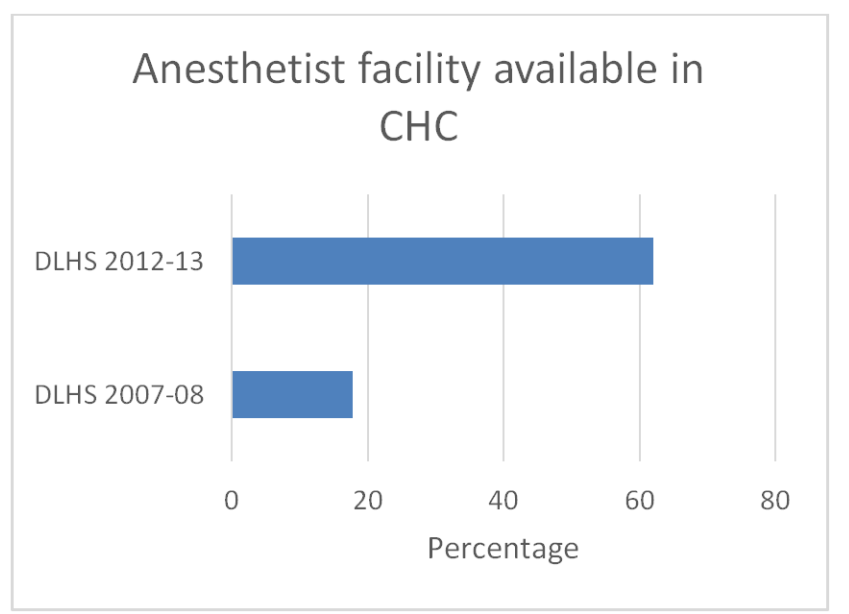

Source: DLHS by Ministry of Health and family welfare Government of India

Figure 6. Percentage of anesthetist facility in CHC in whole Rajasthan.

After applied the Z-test Statistical analysis significantly difference between two populations for large sample size in CHC, PHC and SC. But Water facility provides in sub- center data are significant and Lady Medical officer, Pharmacist and Referral service for delivery sample size data are not significant. Similarly significance level is given below table.

\section{Data Collection and Research Methodology}

The National Health Policy stressed on the provision of preventive, promotive and rehabilitative health services to the people thereby making a shift from medical care to health care. The delivery of Primary Health Care is the foundation of the rural health care system and is an integral part of the national health care system.

Rajasthan was part of the "BIMARU" and Empowered Action Group (EAG) states and fairs poorly on the health and epidemiological parameters by NRHM.

Sub-Centre are peripheral contact points between the Primary Health Care system and the community. One male Multipurpose Worker and one female Multipurpose Worker/ANM are expected to be appointed at each facility. A PHC, on the other hand, is the first connect point between the village community and the Medical Officer. A PHC is expected to have a Medical Officer and 14 Paramedical and other staff. Every PHC under 5 to 6 Sub-Centre's. It should have 4 to 6 beds for patients. By the Government of India NRHM is recognizing the importance of Health in the process of economic and social development and improving the quality of life of our peoples.

PHCs facility should also have essential infrastructure, Staff, equipment and supplies.

Regular power supply of Electricity at SC, $\mathrm{PHC}$ and $\mathrm{CHC}$ is need to improvement day to day like backed up generator and so on. Doctor cannot better perform their duty such as delivery, major/minor operations.

Residential Quarters for M.O. is compulsory provide in the PHC compound then service provide 24 hours because for emergency case innocent people round the clock.

Functional vehicle is also a part of health facility infrastructure so it is also need to improve in rural are specially.

\section{Conclusion}

From table 1, It is concluded that in Sub-Centre the water facilities has not been increased from 2007-08 to 2012-13 similarly in PHC Lady medical officers and referral services for delivery has not been significantly change form 2007-08 to 2012-13, so it is therefore very important to note that the policy makers should emphasized to increase the water facility at sub centers also was not increased referral service for delivery in PHC from DLHS by NRHM survey year 2007-08 to 2012-13. So it is very important to note that the policy makers should emphasized upon to increase the water facility at Sub-Centre as Sub Centre are increasing day by day.

It is fact that in Sub-Centre regular supply of electricity, toilet facilities, and number of labor room has been increased significantly NRHM survey year 2007-08 to 2012-13.

In PHC, the medical officers, ayush doctors, PHC functioning 24 hours regular power supply, having functional vehicle have been increased significantly from NRHM survey from year 2007-08 to 2012-13. In similarity in $\mathrm{CHC}$ number of obstetric gynecologist pediatricians 
anesthetist and health manager have been increased significantly.

It is also observed that in $\mathrm{PHC}$ residential quarter for
M.O., at least 4 beds and at least 10 deliveries conducted have not been significantly increased even it shows the decrement from NRHM survey year 2007-08 to 2012-13.

Table 1. Health Centre facility variables testing.

\begin{tabular}{|c|c|c|c|c|c|c|c|}
\hline \multirow{2}{*}{ Sub Centre variable } & \multicolumn{2}{|c|}{$n_{1}=785 n_{2}=989$} & \multirow{2}{*}{$\begin{array}{l}\text { Z calculate } \\
\text { Value } \\
\end{array}$} & \multicolumn{2}{|c|}{ Level of significance difference } & \multirow{2}{*}{$P_{1}$} & \multirow{2}{*}{$\boldsymbol{P}_{2}$} \\
\hline & HO & H1 & & $5 \%(1.645)$ & $1 \%(2.33)$ & & \\
\hline Regular electricity & $P_{1}=P_{2}$ & $P_{1}<P_{2}$ & 15.13 & Yes & Yes & 0.015 & 0.16 \\
\hline Water & $P_{1}=P_{2}$ & $P_{1} \neq P_{2}$ & 0.46 & No & No & 0.713 & 0.703 \\
\hline Labor room & $P_{1}=P_{2}$ & $P_{1}<P_{2}$ & 8.81 & Yes & Yes & 0.269 & 0.473 \\
\hline PHC variable & \multicolumn{7}{|c|}{$n_{1}=692 n_{2}=722$} \\
\hline Medical Officer & $P_{1}=P_{2}$ & $P_{1}<P_{2}$ & 8.06 & Yes & Yes & 0.62 & 0.813 \\
\hline Lady M.O. & $P_{1}=P_{2}$ & $P_{1} \neq P_{2}$ & 1.178 & No & No & 0.062 & 0.078 \\
\hline Ayush doctor & $P_{1}=P_{2}$ & $P_{1}<P_{2}$ & 10.41 & Yes & Yes & 0.199 & 0.46 \\
\hline Pharmacist & $P_{1}=P_{2}$ & $P_{1} \neq P_{2}$ & 1.85 & Yes & No & 0.007 & 0.018 \\
\hline Residential Quarter for M.O. & $P_{1}=P_{2}$ & $P_{1}>P_{2}$ & 3.69 & Yes & Yes & 0.633 & 0.536 \\
\hline PHC functioning 24 hours & $P_{1}=P_{2}$ & $P_{1}<P_{2}$ & 7.82 & Yes & Yes & 0.569 & 0.765 \\
\hline At least 4 beds & $P_{1}=P_{2}$ & $P_{1}>P_{2}$ & 2.67 & Yes & Yes & 0.899 & 0.852 \\
\hline Regular power supply & $P_{1}=P_{2}$ & $P_{1}<P_{2}$ & 8.87 & Yes & Yes & 0.121 & 0.317 \\
\hline Having functional vehicle & $P_{1}=P_{2}$ & $P_{1}<P_{2}$ & 8.90 & Yes & Yes & 0.114 & 0.308 \\
\hline At least 10 deliveries conducted & $P_{1}=P_{2}$ & $P_{1}>P_{2}$ & 3.84 & Yes & Yes & 0.442 & 0.346 \\
\hline Referral service for delivery & $P_{1}=P_{2}$ & $P_{1} \neq P_{2}$ & 1.23 & No & No & 0.315 & 0.346 \\
\hline Obstetric Gynecologist & $P_{1}=P_{2}$ & $P_{1}<P_{2}$ & 7.84 & Yes & Yes & 0.299 & 0.086 \\
\hline Pediatricians & $P_{1}=P_{2}$ & $P_{1}<P_{2}$ & 19.6 & Yes & Yes & 0.231 & 0.91 \\
\hline Anesthetist & $P_{1}=P_{2}$ & $P_{1}<P_{2}$ & 12.64 & Yes & Yes & 0.178 & 0.62 \\
\hline Health manager & $P_{1}=P_{2}$ & $P_{1}<P_{2}$ & 3.12 & Yes & Yes & 0.028 & 0.08 \\
\hline
\end{tabular}

Table 2. Population of Health Centre according to IPHS norms.

\begin{tabular}{lll}
\hline \multirow{2}{*}{ Centre } & \multicolumn{2}{l}{ Population norm } \\
\cline { 2 - 3 } & Plain areas & Hilly/Tribal area \\
\hline Sub-Centre & 5,000 & 3,000 \\
PHC & 30,000 & 20,000 \\
CHC & 120,000 & 80,000 \\
\hline
\end{tabular}

\section{Implication and Recommendation}

From the comparison of NRHM 2007-08 to 2012-13 survey data; it is observed that there is a need to improve the variables of interest at the health centers. Policy makers/government should provide a sufficient water facility at sub centers; provide lady medical officers, referral services for delivery at PHC level. It is fact that in some variables at sub centre, PHC and $\mathrm{CHC}$ level has been improved significantly even than at PHC level, performance of some variables like residential quarter for medical officers, facility for at least 4 beds and at least 10 deliveries are less, so at PHC level, government should provide some grant to improve infrastructure facility with reference to the above variables.

\section{References}

[1] DLHS-3 by Ministry of Health and Family welfare department of India; https://nrhm-mis.nic.inRajasthan.

[2] DLHS-4 by Ministry of Health and Family welfare department of India; https://nrhm-mis.nic.inRajasthan.

[3] Garner, P., J. Thompson, and D. Donaldson. 1990. "Quality
Assessment of Health Facilities in Rural Papua New Guinea." Health Policy and Planning 5 (1); 49-59.

[4] Rives, M. J. and T. M. Heaney (1995). Infrastructure and local economic development. Regional Science Perspectives. 25 (1), $58-73$

[5] Akin, J. and P. Hutchinson. 1999. "Health-Care Facility Choice and the Phenomenon of Bypassing." Health Policy and Planning 14 (2); 135-51.

[6] Fakayode, B. S, O. A. Omotesho, A. B. Tsoho and P. D. Ajayi (2008). An economic survey of rural infrastructures and agricultural productivity profiles in Nigeria. European Journal of Social Science, 7 (2), 158-171.

[7] G. P. Cimellaro, Cristina Fumo, A. Reinhorn and M. Bruneau (2008). Seismic Resilience of Health Care Facilities. The World Conference on Earthquake Engineering, Beijing China.

[8] Schoeman S, Smuts CM, Faber M, Van Stujvenberg M, Oelofse A, Laubscher JA, Benade AJS and Dhansay MA (2010). Primary health care facility infrastructure and services and the nutritional status of children 0 to 71 months old and their caregivers attending these facilities in four rural dstricts in the Eastern Cape and KwaZulu-Natal provinces, South Africa.

[9] SapnaKaul, Wen You and Kevin J. Boyle (2012). Delivery at Home Versus Delivery at a Health Care Facility-A Case Study of Bihar, India. Agricultural and Applied Economics Association's 2012.

[10] Dr. R. Kavitha (2012) Health Care Industry in India. International Journal of Scientific and Research Publications, Volume 2, Issue 8, August 2012.

[11] Suresh Kumar Patra, D. Satyanarayan Murthy and SubhrajitRath (2013). An Evaluation of the National Rural Health Mission (NRHM) in Odisha. Journal of Health Management 15 (3) 471-480. 
[12] Suresh Kumar Ray (2014). AWARENESS \& UTILIZATION OF NATIONAL RURAL HEALTH MISSION SERVICES AMONG PEOPLE OF SELECTED RURAL AREAS IN THE STATE OF MAHARASHTRA. www.njcmindia.Org Eissn 2229-6816.

[13] Y. Navatha, K. Venkata Reddy and Deva Pratap (2015). Analysis and planning of infrastructural facilities in rural areas using facility index methods. Journal of Geomatics Vol. 9 No. 2 October 2015.
[14] Dr. Abdelhalim E. EI-Farouk, Dr. Abdoul Jelil Niang, Fadhel M. Banjar, Hosham M. O. Karar and Fowzi O. Elamin (2017). DISTRIBUTION OF SELECTED HEALTH FACILITIES AND RESOURCES IN SAUDI ARABIA A GRAPHICAL AND CARTOGRAPHICAL PRESENTATION. European Journal of Pharmaceutical and Medical Research.

[15] S. Gopalakrishnan and A. Branch Immanuel (2017). Progress of health care in rural India: A critical review of National Rural Health Mission. International Journal of Community Medicine and Public Health Pissn 2394-6032. 